\title{
ANÁliSE DOS ASPECTOS ERGONÔMICOS NA COLHEITA DA PIMENTA- DO-REINO (Piper Nigrum), EM UMA PROPRIEDADE NA VILA DO GUARUMÃ NO MUNICÍPIO DE ACARÁ - PA.
}

Glinda Sâmia da Silva Fôro (UNIVERSIDADE DE SANTO AMARO - UNISA) glindaforo@ gmail.com Agnes de Souza Costa (UNIVERSIDADE FEDERAL RURAL DA AMAZÔNIA)

\section{Resumo}

agnes.souzacosta@gmail.com

Os problemas ergonômicos desenvolvidos pela atividade agrícola em geral apresentam características semelhantes pois quase sempre estão associados ao processo de plantio e colheita. O presente trabalho tem como objetivo avaliar os aspectos ergonômicos, identificar riscos e descrever como as atividades são desenvolvidas na colheita da pimenta-do-reino. Para isso, foi realizada uma pesquisa bibliográfica, aplicação de questionários com os trabalhadores para identificar seus perfis e os aspectos relacionados ao trabalho e com os gestores a fim de compreender o processo de produção da pimenta. Logo, podemos perceber que mesmo proporcionando renda, essa atividade causas sérios riscos ergonômicos a essas pessoas, podendo desencadear dores na coluna, propiciando o desenvolvimento de patologias como escoliose, lordose e cifose.

Palavras-chave: Pimenta-do-reino, Ergonomia, Análise Ergonômica, Agricultura, Condições de trabalho.

\section{Introdução}

O Brasil é evidenciado como uma grande potência por ter uma vasta agricultura, sendo representado como uma grande fonte de exportação. Logo após a expansão do mercado brasileiro, durante a década de 90, o agronegócio sofreu um acentuado crescimento, com possibilidades de gerar competitividade neste setor quando comparado aos demais que estavam relacionados à economia doméstica (MARANHÃO e VIEIRA FILHO, 2016).

Marquéz (1986), Silva e Furlani (1999) e Massoco (2008) relatam que cerca de 4\% do Produto Interno Bruto (PIB) mundial são afetados pelos acidentes de trabalhos ocorridos com pequenos agricultores.

Um setor que merece mais atenção para as suas condições ergonômicas é o da Agricultura Familiar, pois mesmo em aspectos de mecanização as atividades são consideradas pesadas, visto que as tecnologias ainda não possuem um direcionamento adequado aos pequenos agricultores, possuindo a visão voltada para os de grande escala (KROMER e GRANDJEAN, 2005). 
A propriedade foco do presente artigo é uma grande produtora da pimenta-do-reino localizada na vila do Guarumã na cidade de Acará, estado do Pará. A produção é oriunda da agricultura familiar e carece de melhores condições quanto à ergonomia no campo e que de certa forma, expõe as pessoas que trabalham nessa atividade à situações de risco.

A expressão "acidente de trabalho no meio rural" está conceituada no artigo 19 da Lei 8.213 de 24 de julho de 1991, que dispõe sobre os planos de benefícios da previdência social e dá outras providências, como

"o que ocorre pelo exercício do trabalho a serviço de empresa ou de empregador doméstico ou pelo exercício do trabalho dos segurados referidos no inciso VII do art. 11 desta Lei, provocando lesão corporal ou perturbação funcional que cause a morte ou a perda ou redução, permanente ou temporária, da capacidade para o trabalho".

A NR 17 - ERGONOMIA enfatiza que a análise ergonômica do trabalho é um processo construtivo e participativo para a resolução de um problema complexo que exige o conhecimento das tarefas, da atividade desenvolvida para realizá-las e das dificuldades enfrentadas para se atingirem o desempenho e a produtividade exigidos.

Tendo observado o crescimento da produção da pimenta-do-reino na região, percebeu-se a importância de demonstrar como as atividades de colheita são desenvolvidas, analisar os aspectos ergonômicos dos trabalhadores e identificar os níveis de riscos enfrentados.

Diante da importância que a ergonomia tem no meio rural, verificou-se que a propriedade, objeto do presente estudo, apresenta deficiências quanto aos aspectos ergonômicos em sua plantação de pimenta-do-reino. Dessa forma, podemos levantar a seguinte questão: quais são essas deficiências e quais riscos elas podem apresentar às pessoas que trabalham nessa atividade?

O presente estudo tem como principal objetivo avaliar os aspectos ergonômicos na produção da pimenta-do-reino, identificar os níveis de riscos em que as pessoas estão expostas no desenvolvimento de suas atividades laborais, através de uma análise dos perfis dos trabalhadores e da forma como as atividades são desenvolvidas nesses ambientes.

\section{Fundamentação teórica}

Os tópicos a seguir apresentam os pontos importantes para o estudo em questão. No primeiro tópico será apresentado um breve histórico da pimenta-do-reino na cidade Acará, o segundo tópico nos mostra a relação da agricultura com a ergonomia e o terceiro tópico nos fala sobre as normas de segurança.

\subsection{Pimenta-do-reino no Pará}


A pimenta-do-reino, também conhecida como pimenta-da-índia, é uma trepadeira com um alto potencial de produtividade e que proporciona lucros a seus produtores, mesmo em condições de pequena escala.

Dois estados brasileiros vêm se destacando na produção de pimenta-do-reino: em primeiro lugar o Pará, com $79 \%$ e em segundo o Espírito Santo, com 13\% da produção nacional (IBGE, 2014). Em 2002, o Pará contribuiu com 85\% do total produzido no país. O restante da produção veio do Espírito Santo (8,5\%) e da Bahia (5,5\%) (IBGE, 2014).

No estado do Pará, em meados da década de 30, a cultura da pimenta-do-reino (Piper nigrum, L.) foi introduzida pelos imigrantes japoneses, desenvolvendo um sistema intenso de produção chegando a ser de grande escala, proporcionando ao país, em 1982, o título de maior produtor e exportador do mundo. Em 1990 e 1991, apesar da crise enfrentada na década, a produção de pimenta-do-reino atingiu grande patamar, idêntico ao verificado em 1982 (HOMMA, 2008).

O período que vai de 1992 a 1999 se caracterizou pela crise no setor decorrente dos baixos preços internacionais, quando os grandes produtores passaram a abandonar os pimentais e abrir espaço para pequenos produtores, que apresentam maior capacidade de sobrevivência, pelo baixo uso de insumos modernos e uso da mão de obra familiar (DESER, 2008).

Esta cultura tem um papel de suma importância para o agronegócio paraense e regional, visto que $80 \%$ da pimenta brasileira produzida é oriunda do estado do Pará. Também possui destaque na geração de empregos consequente da mão de obra gerada pela produção no meio rural (LEMOS et. al 2014). A pimenta-do-reino é amplamente utilizada na agroindústria, na indústria alimentícia e química (ASSIS et al., 2015).

Segundo o Instituto Brasileiro de Geografia e Estatística (IBGE), em 2018 a cidade Acará produziu 1.700 toneladas de pimenta-do-reino enquanto o estado do Pará produziu 33.657 toneladas. A produção de Acará está entre as 10 maiores do estado.

Durante anos a principal fonte de renda da população guarumãense sustentou-se na agricultura, tendo como primeira base de cultivo a mandioca, utilizada para a produção de farinha, o que se perpetuou por anos, mantendo, até os dias atuais, uma forte influência econômica, caracterizando o município como um dos grandes produtores de mandioca.

Devido à grande influência de imigrantes japoneses com a plantação da pimenta-do-reino, a população percebeu uma oportunidade de inovar a agricultura local com grandes perspectivas, e isso levou muitos agricultores a investir. Tendo respostas promissoras, esse novo cultivo 
trouxe muitos benefícios econômicos aos filhos locais, tanto para os investidores, quanto para a população que necessita desta produção para subsídio familiar através da geração de empregos.

\subsection{O trabalho na Agricultura e a Ergonomia}

Durante a criação da Ergonomic Research Society, considerada a primeira sociedade com interesse no estudo das problemáticas de adaptação do homem com o trabalho, surgiu o termo ergonomia, criado pelo inglês Murrel, no ano de 1949 (LAVILLE, 1977).

Sendo assim, Marcon (2013) diz que a ergonomia tem como intuito identificar os fatores de sinistros que causam riscos à saúde do trabalhador, desenvolvendo métodos que proporcione um ambiente seguro diminuindo os riscos aos indivíduos. Pheasant (1988) enfatiza que a ergonomia adapta o trabalho ao trabalhador e o produto ao usuário, tendo como foco principal o homem e os elementos que o envolve.

Menegat e Fontana (2010, p. 55), relata que os acidentes que mais ocorrem na atividade rural são:

[...] quedas e agressões por animais de grande porte, como cavalos e vacas; amputação de dedo ao manusear máquina de moer carne; fratura de membros inferiores ao tocar, por descuido, em correia do motor de máquina ligada, cortes com ferramentas manuais e amputação de dedo ao cortar lenha.

Ao analisar os riscos relatados pelos autores é possível detectar que os principais malefícios dentro da atividade laboral na agricultura são oriundos da própria atividade, ou seja, da rotina de trabalho desenvolvida através do acúmulo de cansaço, que atrapalha o estado psicológico do trabalhador.

Para Abrahão e Pinho (1999), a finalidade de uma análise ergonômica é melhorar as condições de trabalho de forma contínua, levando em consideração a produção, ou seja, respeitando seus limites. Nessa perspectiva, é proposta uma definição da intervenção ergonômica com objetivo de propiciar melhorias. Por trás desta noção de melhoria da relação homem - trabalho, existe o agente da ação (o ergonomista), o sujeito da ação (o trabalhador) e a própria ação (o trabalho). Assim, o trabalho seria o mediador da construção da saúde, de forma que a melhor relação homem - trabalho não é a exclusão do trabalho, mas sim uma relação harmônica entre os dois - trabalho/saúde.

Segundo os autores Anaruma e Casarotto (1996) os aspectos biomecânicos e fisiológicos da postura em pé e sentada, a permanência por períodos prolongados de tempo numa postura 
fixa, os limites de tolerância para levantamento de peso, o tipo de mobiliário adequado, etc., são estudados de forma bastante intensa pelos ergonomistas.

Ao desenvolverem suas tarefas são exigidos dos trabalhadores rurais consideráveis esforços físicos, posturas incômodas sob condições ambientais desfavoráveis, levando em conta que no ambiente de trabalho agrícola parece existir uma grande diversidade de classes de risco conciliável com a verificação do alto grau de variedades dessas tarefas nessas atividades. A contribuição da ergonomia se dá justamente pelo seu caráter multidisciplinar, integrando conceitos das ciências sociais com os avanços tecnológicos, tendo como resultado o aumento da capacidade produtiva individual, redução de acidentes de trabalho e a melhoria das condições de saúde da população trabalhadora (ABRAHÃO, 2006).

\subsection{Normas Regulamentadoras}

Apesar das vantagens econômicas, o cultivo da pimenta-do-reino trouxe diversos problemas ergonômicos para os trabalhadores. Dentre os trabalhos que demandam uma enorme quantidade de esforço físico está o trabalho agrícola, tendo um alto consumo de energia do agricultor. Segundo a literatura, esta atividade é um dos ramos produtivos que geram altos riscos ergonômicos podendo desenvolver distúrbios musculares e incapacidade nos trabalhadores (DAVIS; KOTOWSK, 2007; DRISCCOL et al., 2014).

Para segurança e melhor qualidade de vida no trabalho dos empregados algumas normas regulamentadoras foram implementadas, entre elas está a NR 17 - ERGONOIA, que tem como intuito estabelecer parâmetros que permitam a adaptação das condições de trabalho, as características psicofisiológicas dos trabalhadores, proporcionando conforto, segurança e um melhor desempenho.

Como forma de agregar também foi implementada a NR 31 - Segurança e Saúde no Trabalho e na Agricultura, Pecuária, Silvicultura e Exploração Florestal e na Aquicultura, que visa o desenvolvimento das atividades relacionadas, estabelecendo melhorias na organização e no ambiente de trabalho. Segundo essas normas os EPI's adequados para executar uma atividade de campo são: bota com bico de ferro, perneira, chapéu árabe ou chapéu de palha, luva, calça, óculos de proteção e camisas com mangas compridas.

\section{Metodologia}

A pesquisa caracteriza-se como exploratória, que segundo Gil (2002, p.41) “estas pesquisas têm como objetivo proporcionar maior familiaridade com o problema, com vistas a torná-lo mais explícito ou a constituir hipóteses”. 
Para Selltiz et al (1967, p. 63 apud GIL, 2002, p. 41), “ essas pesquisas envolvem: (a) levantamento bibliográfico; (b) entrevistas com pessoas que tiveram experiências práticas com o problema pesquisado; e (c) análise de exemplos que "estimulem a compreensão".

Dessa forma, foi realizado um levantamento bibliográfico acerca dos assuntos relacionados à ergonomia, histórico da pimenta-do-reino no estado do Pará e a ergonomia na agricultura. Para Fonseca (2002), a análise de riscos ergonômicos pode estar associada a diversos fatores, o que demonstra a necessidade de uma maior compreensão. Com isso, se faz necessário que a academia reconheça os riscos que envolvem este processo, a fim de buscar alternativas que atuem como um interventor na prática.

Para Boccato (2006, p. 266) "a pesquisa bibliográfica busca a resolução de um problema (hipótese) por meio de referenciais teóricos publicados, analisando e discutindo as várias contribuições científicas".

No mês de outubro de 2019, foi desenvolvida uma entrevista com 27 colaboradores que trabalham na produção de pimenta-do-reino da região guarumãense e dois gestores da propriedade. As questões abordadas com os trabalhadores foram relacionadas à forma que eles trabalham e o perfil de cada um quanto à idade, sexo, escolaridade, acidentes de trabalho, dores, entre outras perguntas. A entrevista com os gestores teve o objetivo de abordar aspectos relacionados à produção e à visão sobre os aspectos ergonômicos do trabalho.

A análise dos dados foi quali-quantitativa. A análise qualitativa, de acordo com COSTA (2018), tem por objetivo compreender diferentes aspectos de um fenômeno, de forma que podemos aprofundar e intensificar o intuito de expressar a real dimensão do objeto a ser pesquisado. A análise quantitativa, segundo Gil (2002, p.134), “as categorias são frequentemente estabelecidas apriori, o que simplifica sobremaneira o trabalho analítico". Dessa forma, foi possível a elaboração de gráficos com os resultados da entrevista.

\section{Resultados}

\subsection{Descrição do ambiente de trabalho}

O presente estudo foi desenvolvido em uma propriedade na Vila do Guarumã, localizada na PA 252, a $18 \mathrm{~km}$ da Cidade de Acará. Este nome é dado devido à grande quantidade da palmeira guarumã nas margens dos igarapés existentes na entrada da localidade, advindo da família das marantáceas do gênero Ischinosiphon Koern, facilmente encontradas nas margens dos rios, em solo alagado (várzea) (VALENTE E ALMEIDA, 2001). 
A propriedade estudada apresenta uma área de 170 metros de frente e 1000 metros de fundos, tendo como cultivo alternativo o cacau, cupuaçu, coco e açaí em média escala e como foco a pimenta-do-reino, com oito mil pés e um rendimento por pé entre $2 \mathrm{~kg}$ e $2,5 \mathrm{~kg}$, com uma produção de vinte toneladas de pimenta (verde), em período de safra.

A produção da pimenta-do-reino pelos colaboradores vai desde o preparo do solo para o plantio até a colheita, identificando-se em todas as etapas riscos ergonômicos, mas com maior exposição durante a colheita, que acontece uma vez ao ano, no período de safra que se inicia no mês de agosto e termina em setembro, contudo, podendo se perpetuar até início de dezembro.

\subsection{Análise dos Resultados}

Os gráficos a seguir demonstram o resultado das entrevistas com os trabalhadores.

Gráfico 1 - Sexo

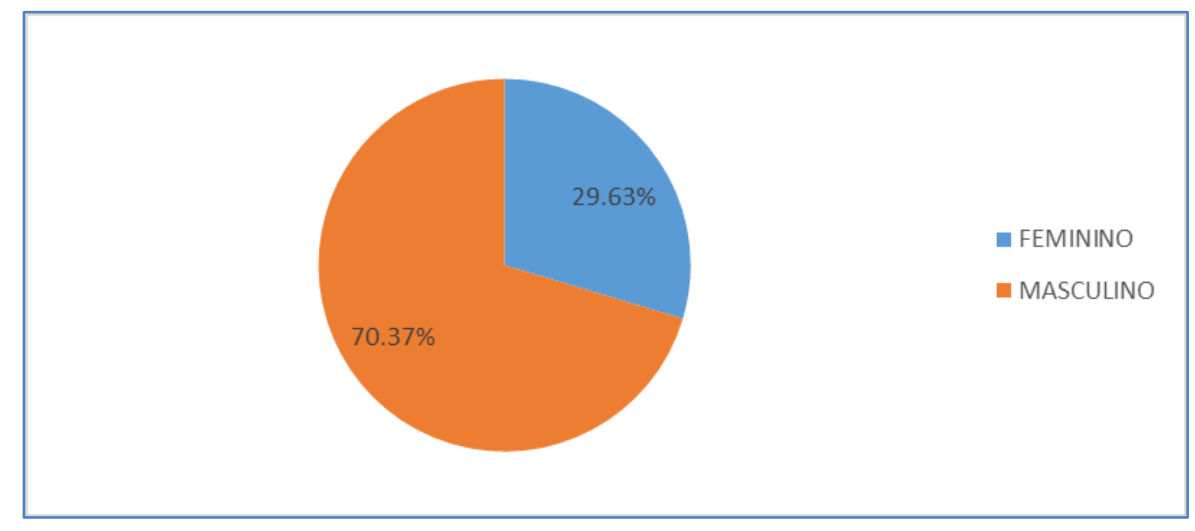

Fonte: Resultados da Pesquisa (2020)

O gráfico 1 representa o percentual de homens e mulheres que trabalham na produção da pimenta-do-reino, o resultado mostra uma maior representação dos homens nessa atividade com $70,37 \%$ e com $29,63 \%$ de mulheres. 
Gráfico 2 - Escolaridade

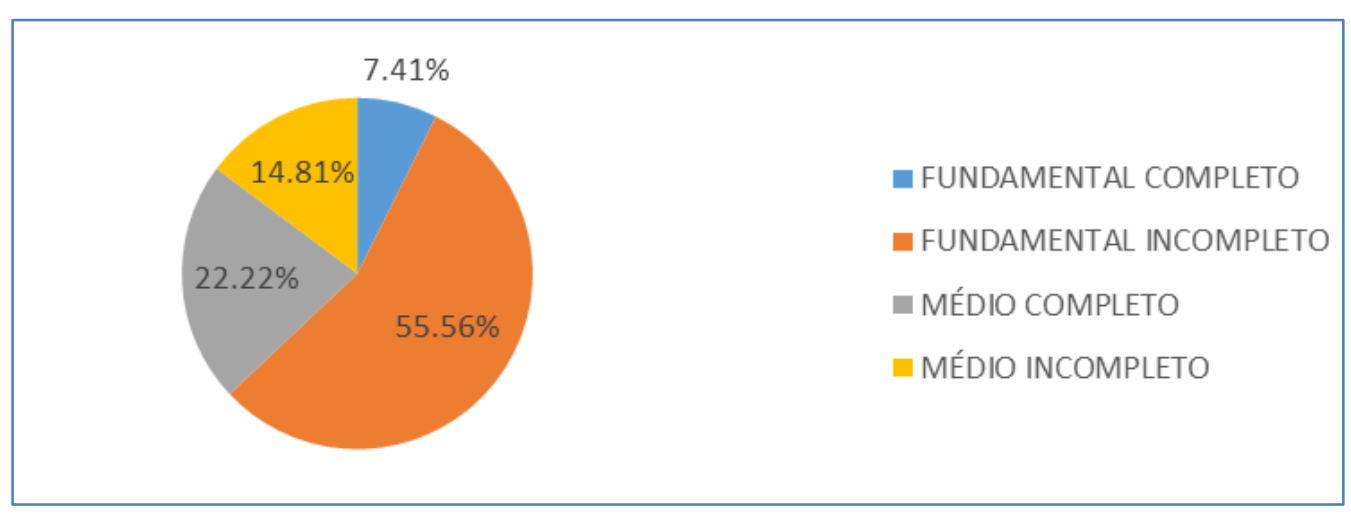

Fonte: Resultados da Pesquisa (2020)

O gráfico 2 mostra o grau de escolaridade dos colaboradores, o resultado demonstra que $55,56 \%$ dos entrevistados possuem ensino fundamental incompleto, 22,22\% possuem ensino médio completo, $14,81 \%$ possuem ensino médio incompleto e $7,41 \%$ possuem ensino fundamental completo.

Gráfico 3 - Faixa etária

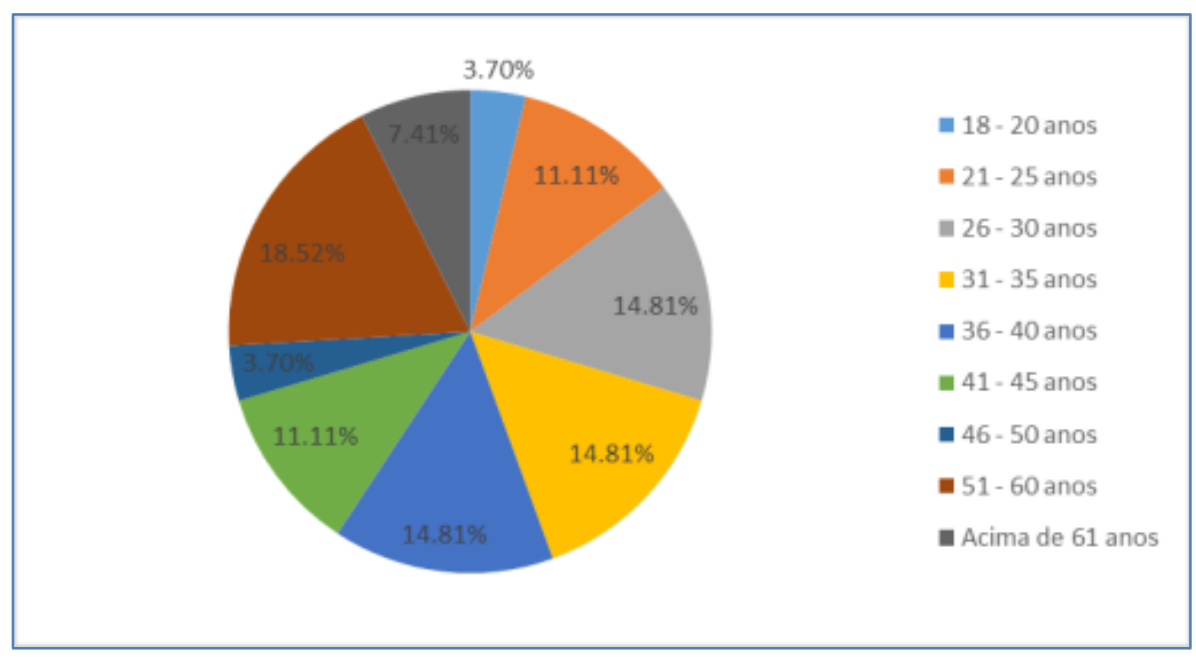

Fonte: Resultados da Pesquisa (2020)

O gráfico 3 representa a faixa etária dos trabalhadores. O resultado nos mostra que a faixa etária de 51 a 60 anos possui 18,52\% das ocorrências, 26 a 30 anos possui 14,81\%, igualandose às faixas etárias de 31 a 35 anos e 36 a 40 anos. As menores ocorrências estão na faixa de 18 a 20 anos e 46 a 50 anos com $3,70 \%$. 
Gráfico 4 - Tempo de Execução da Atividade

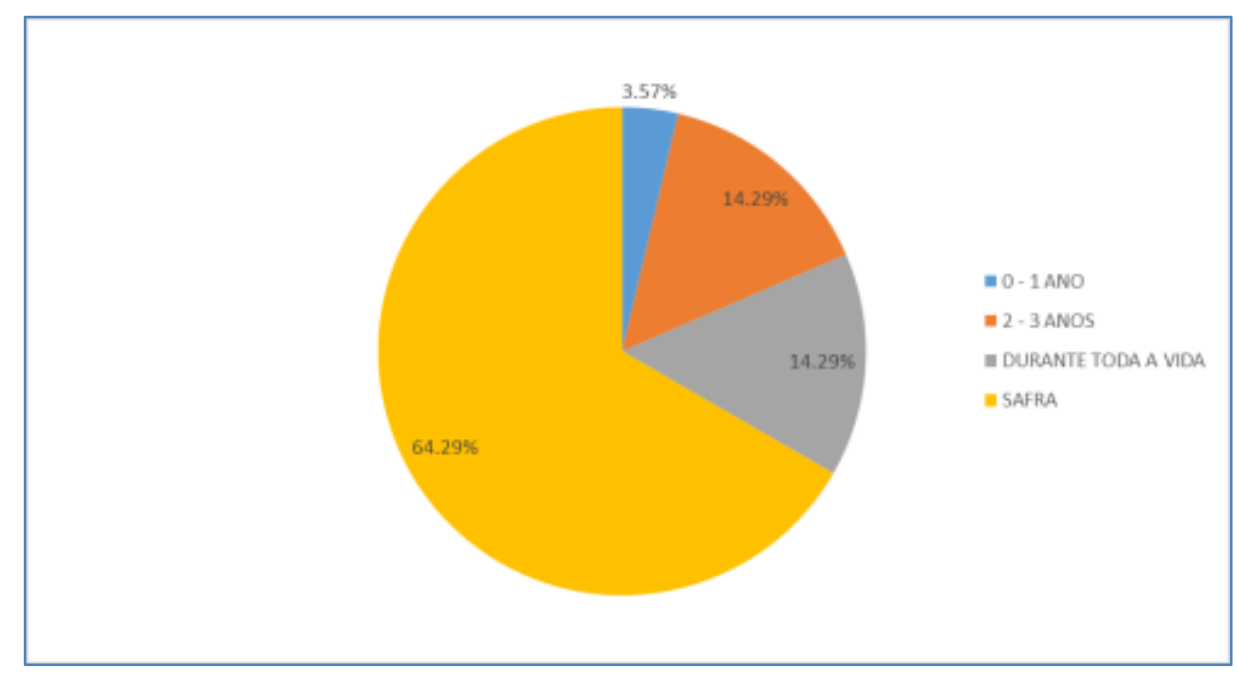

Fonte: Resultados da Pesquisa (2020)

O gráfico 4 representa o tempo em que essas pessoas executam a atividade da produção da pimenta-do-reino. Observa-se que o maior índice ocorre durante o período de safra com 64,29\%. O período de 2 a 3 anos representa 14,29\% das respostas, o mesmo resultado se dá pelas respostas dos trabalhadores que disseram que trabalham nessa atividade por toda a vida. $3,57 \%$ se caracteriza pelo período de menos de 1 ano de trabalho.

Gráfico 5 - O entrevistado é o único que executa a atividade na família?

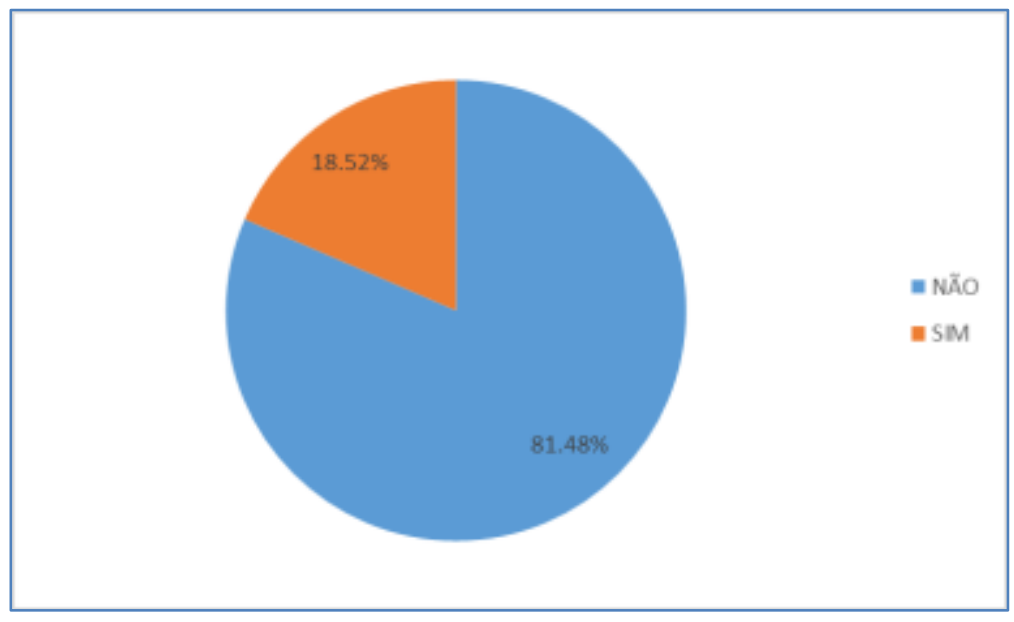

Fonte: Resultados da Pesquisa (2020)

O gráfico 5 mostra com $81,48 \%$ que o entrevistado não é o único da família que executa a atividade. 
Gráfico 6 - Motivo da escolha pela atividade

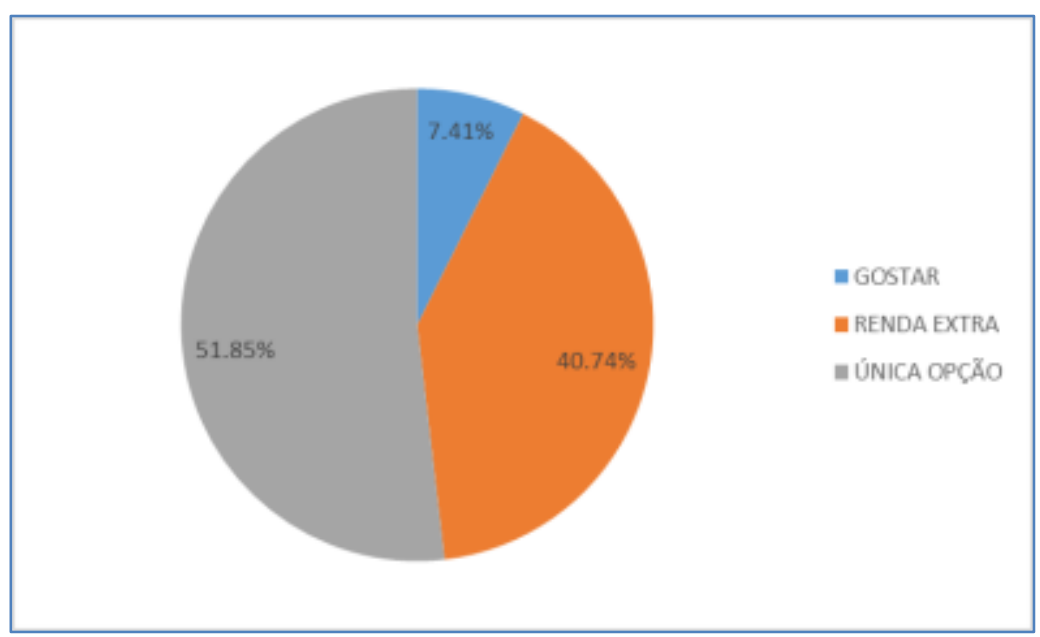

Fonte: Resultados da Pesquisa (2020)

O gráfico 6 mostra o motivo da escolha pela atividade. Observa-se que 51,85\% das respostas são de que a atividade em questão é a única opção que o entrevistado tem de trabalho. A renda extra é caracterizada por $40,74 \%$ das respostas e apenas $7,41 \%$ porque gostam da atividade.

Gráfico7 - Utilização adequada de EPI

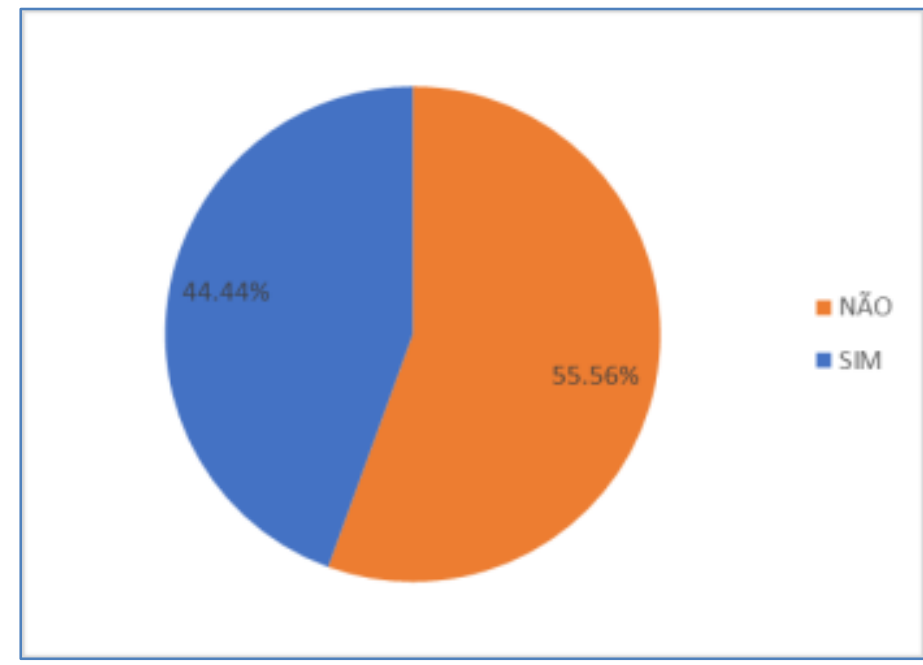

Fonte: Resultados da Pesquisa (2020)

O gráfico 7 mostra se os colaboradores utilizam ou não EPI adequado e os resultados mostram que $55,56 \%$ não utilizam e $44,44 \%$ utilizam. 
Gráfico 8 - Treinamento X Utilização de EPI

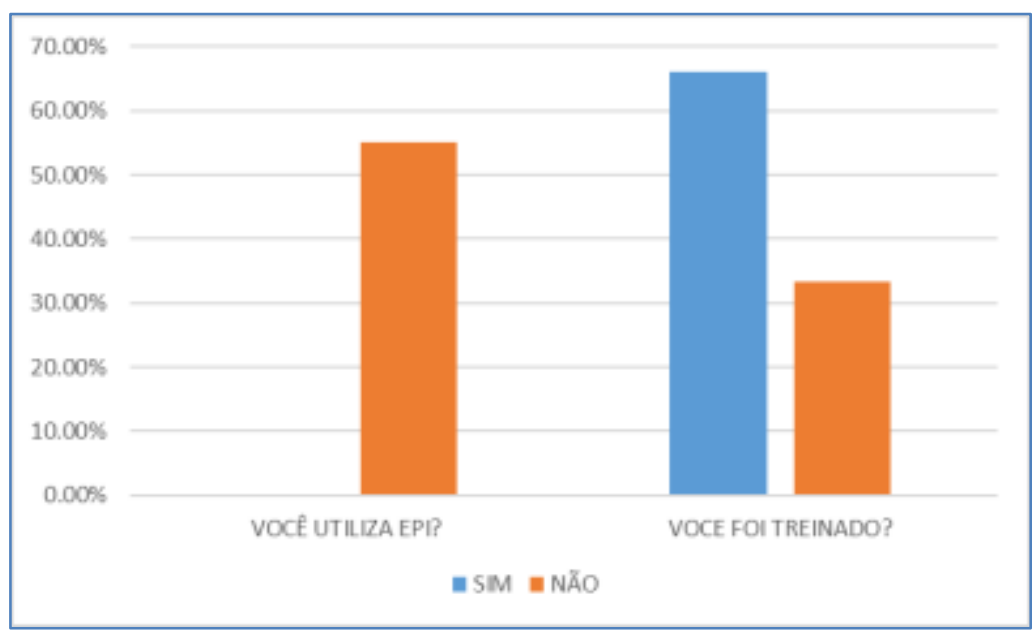

Fonte: Resultados da Pesquisa (2020)

O gráfico 8 mostra a relação treinamento e utilização de EPI. O resultado mostra que dos 55\% dos entrevistados que não utilizam EPI adequado, 66,66\% foram treinados e 33,33\% não foram treinados.

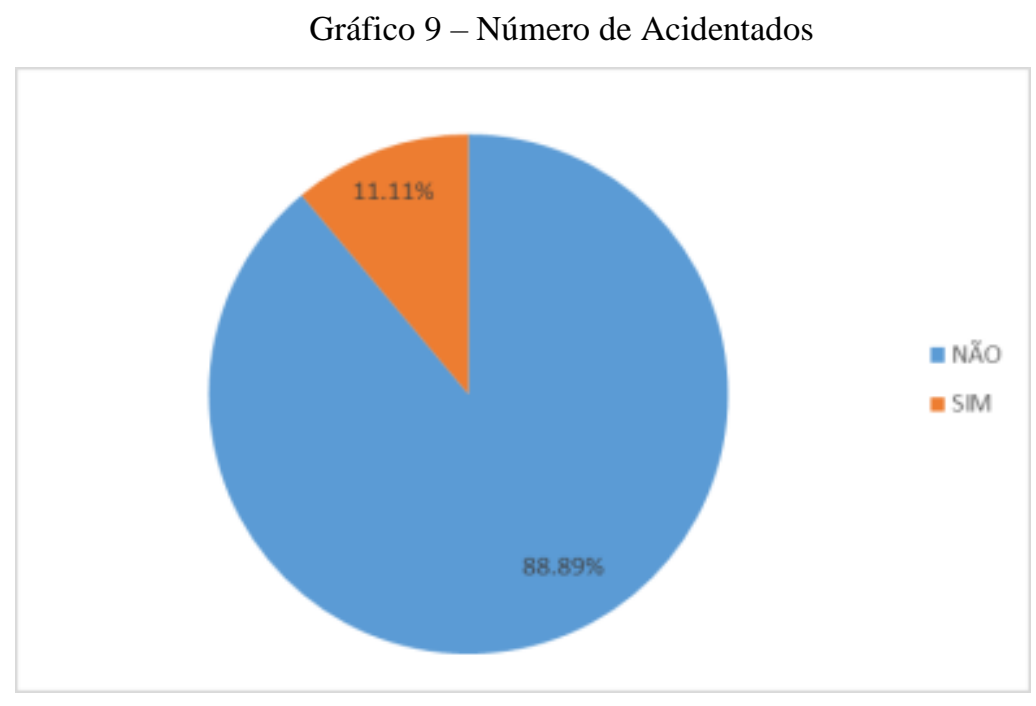

Fonte: Resultados da Pesquisa 2020

O gráfico 9 demonstra que $11,11 \%$ dos entrevistados sofreram acidentes e os que não sofreram representam $88,89 \%$ das respostas.

Quando perguntados se percebem ou não a presença de dores, 22,22\% responderam não e $77,78 \%$ responderam que sentem dores oriundas da atividade. 
Gráfico 10 - Classificação das Dores

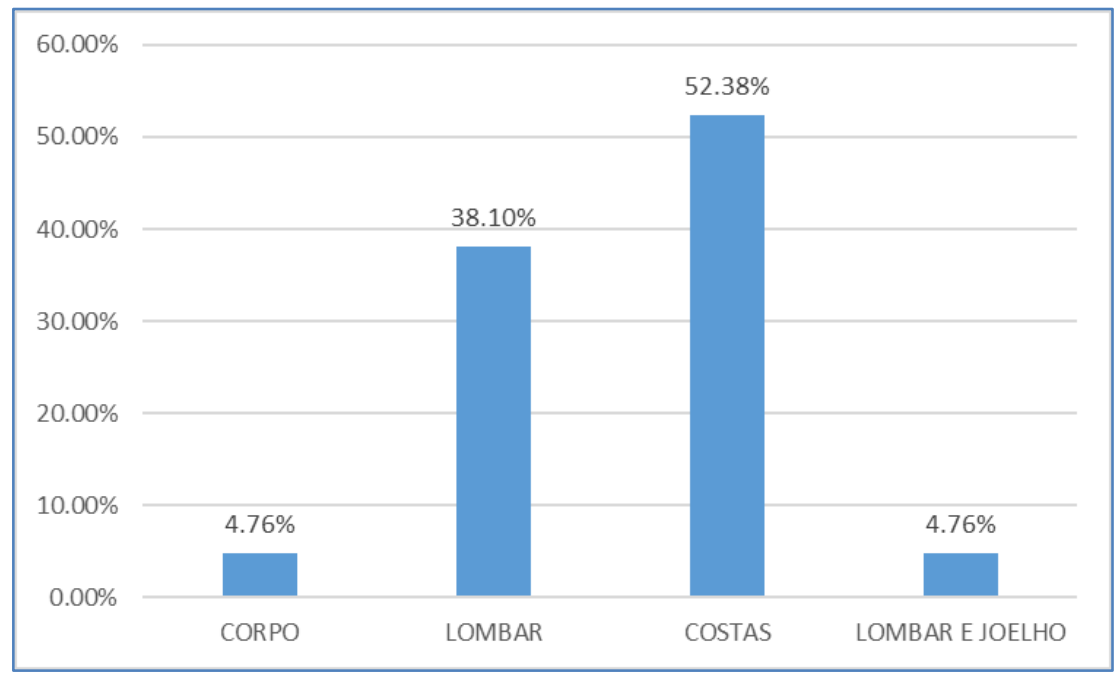

Fonte: Resultados da Pesquisa (2020)

O gráfico 10 representa a classificação das dores, ou seja, onde as pessoas mais percebem a presença. O local do corpo onde os entrevistados mais sentem dor é nas costas, representando $52,38 \%$, seguido pela lombar com $38,10 \%$, lombar e joelho com $4,76 \%$ e no corpo em geral com $4,76 \%$.

Ao analisar o gráfico 10, podemos associar os resultados à postura dos trabalhadores nas diversas etapas que compõem as atividades em geral do cultivo da pimenta. Para comprovar esses resultados, durante a visita à propriedade para a realização das entrevistas, foi possível identificar as causas dessas dores. A figura 1 nos mostra como essa atividade ocorre em termos ergonômicos na etapa da colheita.

Figura 1: Postura dos trabalhadores na colheita da pimenta-do-reino.
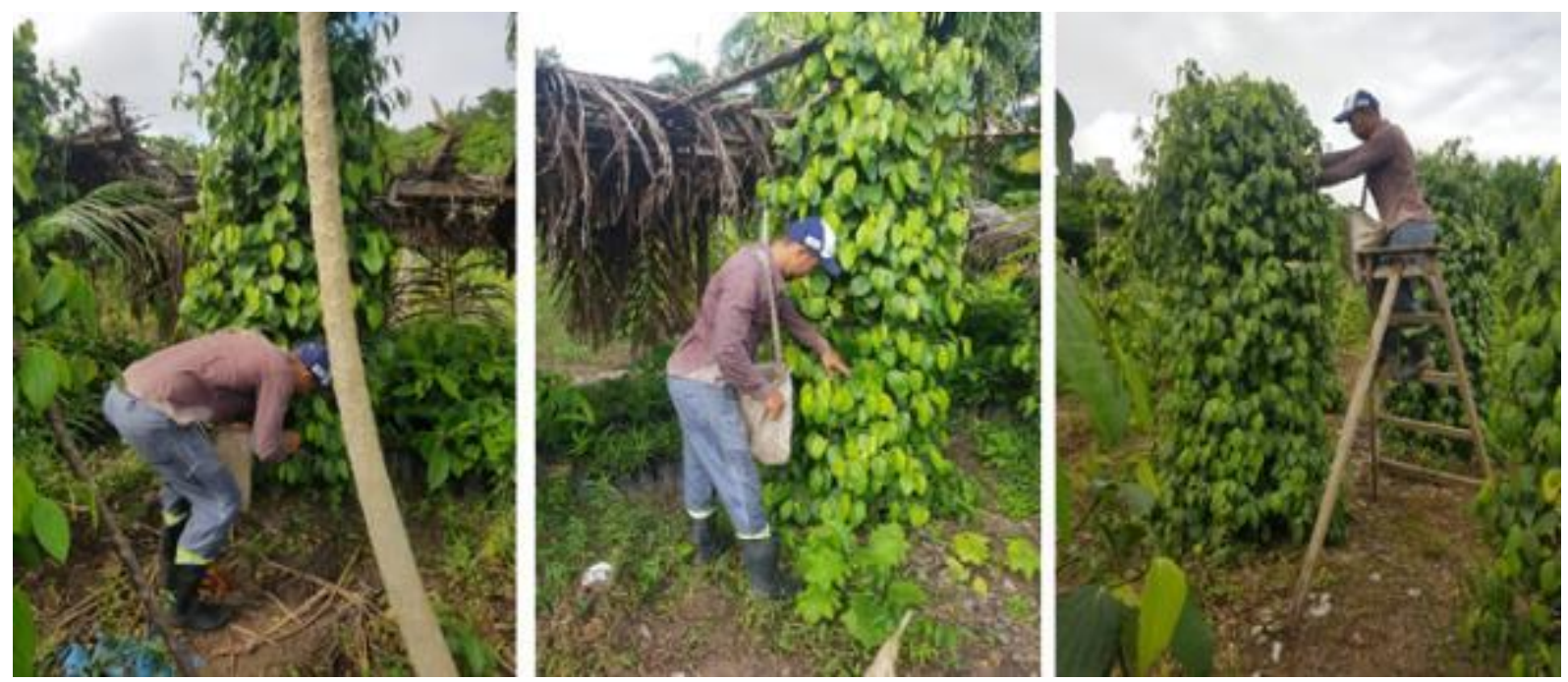

Fonte: Resultados da pesquisa (2020) 
As fotos demonstram que para realizar a colheita da pimenta o colaborador necessita utilizar um saco que fica apoiado no ombro (bisaco), que conforme aumenta a quantidade colhida, mais pesado ele fica. $\mathrm{O}$ trabalhador necessita abaixar-se várias vezes para fazer a colheita da pimenta. Na figura podemos observar que o trabalhador não se abaixa de forma adequada e a repetição desse movimento é o principal causador das dores na lombar e nas costas. A escada (trepadeira) utilizada parar alcançar as partes mais altas do pé de pimenta também favorece para o aparecimento de dores nas costas e na lombar, principalmente por ter que se contorcer para chegar na posição adequada para realizar a colheita. A trepadeira também é a causa de muitos acidentes, principalmente se o terreno for irregular ou não estiver limpo.

\section{Conclusão}

Ao analisar os resultados da pesquisa podemos perceber que o objetivo foi atingido. Foi possível identificar o perfil dos trabalhadores e analisar os aspectos ergonômicos do trabalho na safra da pimenta-do-reino. Identificamos também os riscos que esses trabalhadores estão submetidos durante o trabalho.

A produção da pimenta-do-reino é uma das atividades de suma importância para as famílias da Vila do Guarumã, proporcionando emprego, sendo esta muita das vezes a única fonte de renda e em determinadas situações para toda a família. A maioria dos entrevistados $(51,85 \%)$ disse que é a única opção de trabalho, que pode ser justificada pela baixa escolaridade já que $55,56 \%$ dos entrevistados disseram ter o ensino fundamental incompleto.

Diante das informações obtidas no desenvolvimento do presente trabalho as etapas de produção da pimenta-do-reino, assim como sua colheita, proporcionam diversos riscos para os colaboradores, entre eles problemas ergonômicos como: dores nas costas, na lombar e no joelho. As dores nas costas associadas às dores na lombar somam 95,24\% das dores que eles sentem ao executar as atividades e que foram comprovadas quanto à postura representada na figura 1.

Quanto aos riscos de acidente, entre os principais, podemos citar o uso da trepadeira que pode causar a queda do trabalhador, além da má postura. Devido aos riscos enfrentados nesta atividade, pode ser que a renda futuramente seja comprometida com problemas que afete toda a coluna, causados pela má postura desde a região cervical (pescoço) até a região lombar (parte próxima ao quadril), além de desenvolver patologias como: escoliose, lordose e cifose, situações que podem ocasionar o afastamento do funcionário. 
O uso de EPI's se dá por conta própria do trabalhador, visto que aqueles que receberam treinamento disseram que o mesmo ocorreu em algum momento de sua vida e que na propriedade onde a pesquisa foi realizada não há disponibilização dos equipamentos e de treinamentos necessários.

Um fator que também contribuiu para esses resultados é a falta de conhecimento dos gestores sobre normas de segurança, proporcionando aos funcionários condições inadequadas de trabalho. Como forma de tentar diminuir esses índices demonstrados, os dados da pesquisa serão disponibilizados aos gestores e serão oferecidas propostas para que eles possam proporcionar melhorias de condições de trabalho aos seus colaboradores.

\section{REFERÊNCIAS}

ABRAHÃO, F. Roberto et. al. Organização e Análise Ergonômica do Trabalho: Um estudo comparativo entre a agricultura orgânica e a convencional. Campinas, 2004.

ASSIS, B.V.R.; MEIRA, F.O.; PINA, V.G.S.S.; ANDRADE, G.F.; COTRIM, B.A.; RESENDE, G.O.; D’ELIA, E.; SOUZA, F.C. Efeito inibitório do extrato de Piper nigrum L. sobre a corrosão do aço carbono em meio ácido. Revista Virtual de Química, v.7, p.1830-1840, 2015. DOI: https://doi.org/10.5935/1984-6835.20150105

BAUER, Martin W.; GASKELL, George; ALLUM, Nicholas C. Qualidade, quantidade e interesses do conhecimento: evitando confusões. In: manual prático. Petrópolis: Vozes, 2008. (Org.). Pesquisa qualitativa com texto, imagem e som: um

BOCCATO, V. R. C. Metodologia da pesquisa bibliográfica na área odontológica e o artigo científico como forma de comunicação. Rev. Odontol. Univ. Cidade São Paulo, São Paulo, v. 18, n. 3, p. 265-274, 2006.

BRASIL. LEI No 8.213, DE 24 DE JULHO DE 1991. Da finalidade e dos princípios básicos da previdência social. Disponível em: http://www.planalto.gov.br/ccivil_03/leis/18213cons.htm. Acesso em: 06 de fevereiro de 2020.

CHAMIÇO, Angel Mariana Alvarenga. Diagnóstico sociolaboral e de saúde dos trabalhadores rurais do entorno do Distrito Federal: em busca de identificar um perfil. 2016. Monografia (Graduação em Saúde Coletiva), Universidade de Brasília. Ceilândia, 2016.

COSTA, Wagner. Fernandes. et al. Uso de instrumentos de coleta de dados em pesquisa qualitativa: um estudo em produções científicas de turismo. Turismo-Visão e Ação, v. 20, n. 1, p. 02-28, 2018.

DEIMLING, M. F.; PESAMOSCA, D. Análise Ergonômica do Trabalho (AET) emuma empresa de confecções.Iberoamerican Journal of Industrial Engineering,v. 6, n. 11, p. 37-58, 2014.

DESER. Departamento de estudos sócio-econômicos. Secretaria de Agricultura Familiar. Curitiba, novembro, 2008.

DREBES, Laila Mayara et al. Acidentes típicos do trabalho rural: um estudo a partir dos registros do hospital universitário de Santa Maria, RS, Brasil.Revista Monografias Ambientais, v.13, n.4, p.3467-3476 set./dez. 2014.

FONSECA, João José Saraiva. Metodologia da pesquisa científica. Fortaleza: UEC, 2002, Apostila.

GIL, A. C. Como elaborar projetos de pesquisa. São Paulo, Editora Atlas, 2002.

HOMMA, A. K. O. Extrativismo, Biodiversidade e Biopirataria na Amazônia. Brasília-DF, Embrapa Informação Tecnológica, 2008.

IBGE. 2014. Instituto Brasileiro de Geografia e Estatística. IBGE cidades. Disponível em:

https://cidades.ibge.gov.br/brasil/pa/acara/panorama. Acesso em: 06 de fevereiro de 2020.

KROEMER, K. H. E.; GRANDJEAN, E. Manual de ergonomia: adaptando o trabalho ao homem. 5. ed. Porto Alegre, RS: Bookman, 2005. 327 p. 
LAVILLE, Antoine. Referências para uma história da ergonomia francófona. In: Ergonomia.

LEMOS, O.F. de; TREMACOLDI, C.R.; POLTRONIERI, M.C. (Ed.). Boas práticas agrícolas para aumento da produtividade e qualidade da pimenta-do-reino no Estado do Pará. Brasília: Embrapa, 2014.

MARANHÃO, Rebecca Lima Albuquerque; VIEIRA FILHO, José Eustáquio Ribeiro. A dinâmica do crescimento das exportações do agronegócio brasileiro. Textos para discussão, Brasília, nov. 2016.

MARCON, Luiz Carlos. Análise ergonômica das condições do trabalho de operação de tratores agrícolas. 2013. 81f. Monografia (Especialização em Engenharia de Segurança do Trabalho), Universidade do Extremo Sul Catarinense, Criciúma. 2013.

MENEGAT, Robriane Prosdocimi; FONTANA, Rosane Teresinha. Condições de trabalho do trabalhador rural e sua interface com o risco de adoecimento. Ciência Cuidado e Saúde, v.9, n.1, p.52-59, jan./mar. 2010.

MINISTÉRIO DO TRABALHO E EMPREGO. Norma Regulamentadora 17 - Ergonomia. Brasília, 1978.

PHEASANT, S. Bodyspace: anthropometry, ergonomics and the design of work. London: Taylor \& Francis, 1988.

VALENTE, R. \& ALMEIDA, S.(2001) - As Palmeiras de Caxiuanã. Museu Paraense Emílio Goeldi. 54 p. Belém. 